\title{
Behavioral analysis of rock bream Oplegnathus fasciatus reveals a strong attraction potential for sea urchin extracts
}

\author{
S. K. Tilan Chamara Duminda, Yeo-Reum Kim, Jong-Myoung Kim \\ Department of Fisheries Biology, Pukyong National University, Busan 48513, Korea
}

\begin{abstract}
Monitoring fish movement is important to understand how physiology adapts to environmental change. To explore the applicability of a video tracking system for determining if chemical cues attract or repel aquatic animals, the movement patterns of rock bream, Oplegnathus fasciatus, were analyzed upon exposure to various materials, including extracts of sea urchin, rock worm, bait worm, krill, barley kernel, and commercial fish feed. Pellets were prepared by mixing freeze-dried tissues with a cellulose and corn flour mixture. Behavioral analysis was carried out with five fish that had been acclimated in the adaptation zone of a Y-shaped tank. Preference toward chemical cues was quantified by assessing the frequency rock bream were observed in a discrete zone around the test material located at the end of each arm and the duration each fish stayed in each zone. The analysis of fish movement upon exposure to commercial feed and barley kernel at each end, respectively, indicated a clear preference toward the feed relative to the barley kernel. Movement responses were further tested with pellets containing extracts of sea urchin, one of the species collected on a large scale, and other materials including krill and worms. A stronger preference toward sea urchin (100\%) was observed based on the duration of stay in the test zone, compared to krill $(90.1 \pm 44.2 \%)$, bait worm (81.1 $\pm 39.1 \%)$, rock worm $(73.7 \pm 28.9 \%)$, and barley $(63.9 \pm 25.9 \%)$, under the conditions tested. A detailed comparison of rock bream movements toward each material revealed significant differences in frequency and duration, respectively, between pairs of test materials including krill $(74 \pm 29.8$ and $375.6 \pm 118.9)$ vs. rock worm $(41.5 \pm 18.7$ and $160.2 \pm 42.6)$, krill $(86.3 \pm 22.9$ and 477.1 $\pm 84)$ vs. bait worm $(36.2 \pm 5.5$ and $166.1 \pm 50.7)$, and rock worm $(45.9 \pm 26.2$ and $213.7 \pm 100.1)$ vs. bait worm (34.6 \pm 21.7 and $159.5 \pm 98.5$ ). Rock bream exhibited preference for the test materials in the following order: commercial fish feed $>$ sea urchin $>$ krill $>$ rock worm $>$ bait worm $>$ barley. The results suggest a higher potency of sea urchin extract as a rock bream fishing bait compared to the other materials that are used as commercial bait.
\end{abstract}

Keywords: Sea urchin, Rock bream, Fish attraction, Behavior monitoring, Bait 


\section{Introduction}

Behavioral analyses are important for understanding various physiological aspects of an animal's response to environmental changes as well as their health status. Aquatic animals are a good model for monitoring animal behavior, as chemical cues are spread by diffusion in the more homogeneous water medium. Fish detect myriad environmental signals that affect their behaviors, such as foraging, courtship, schooling, attraction, and aggression (Firestein, 2001; Kermen et al., 2013). Underwater acoustic cameras and vision-based tracking systems have been employed to monitor such fish movements in the aquatic environment (Kane et al., 2005; Kuklina et al., 2012; Niu et al., 2018). Although the former method is more suitable for analyzing behavior in large-scale experiments (Jang et al., 2016), video tracking is more convenient for detecting chemical cues that elicit a behavioral response in a smaller model system.

Rock bream, Oplegnathus fasciatus, is a marine fish that lives in rocky coastal areas off Korea. It is a popular species of high economic value, with interest in this species increasing for aquaculture production as well as for fishing. Some studies have investigated the physiology of rock bream associated with temperature and photoperiod, but relatively little is known about its physiology in terms of detecting chemicals present in the environment. Various materials, including squid, krill, and worms, are used as bait for rock bream fishing, although there has been an increasing demand to develop more efficient and environmentally friendly alternatives. It is important to find such materials that will attract rock bream efficiently but can be obtained at a lower cost.

Sea urchins are spiny marine echinoderms belonging to the class Echinoidea and considered a model organism for early development. One species, Strongylocentrotus nudus, is predominantly distributed along intertidal and subtidal sea-bottom (Agatsuma, 2007) areas off the northeast Pacific coast. Sea urchins play a critical role in maintaining the balance between corals and algae (Harrold \& Pearse, 1987; Lang \& Schroeter, 1976; Lawrence, 2007; Valentine \& Heck, 1999). In particular, a high-density population of sea urchins overgrazing attached seaweeds has been identified as one of the most destructive factors in fish breeding grounds. Therefore, controlling the number of sea urchins that invade seaweed areas is a challenge in protecting the environment, including the reinforced marine forest off the eastern coast of Korea. Some efforts have been made to remove sea urchins from the area, resulting in a disposal prob- lem as tons of collected sea urchins have to be dealt with. This could be alleviated by finding an efficient way to use or recycle the sea urchin biomass. Sea urchins with eggs have been used as food in Asian countries, but most of the sea urchins are thrown out. As many sea urchins are found in marine forest areas where the omnivorous rock bream is present, their potential use as bait for rock bream fishing has been suggested. Thus, in this study, we compared the efficacy of a sea urchin extract to that of other foods, including rock worm, bait worm, krill, and barley kernel, for use as fishing bait by monitoring the behavioral response of the rock bream upon exposure to these cues.

\section{Materials and Methods}

\section{Experimental animals and tank}

Rock bream (weight $8.8 \pm 1.8 \mathrm{~g}$; length $7.4 \pm 0.6 \mathrm{~cm}$ ) were obtained from a commercial aquaculture facility. The fish were maintained in a tank with $33 \pm 2$ ppt recirculating sea water at $20 \pm 2{ }^{\circ} \mathrm{C}$ and fed $3 \%$ of their body weight with commercial fish feed. The sea urchins were obtained from eastern coastal areas of Korea with the help of the Korea Fisheries Resources Agency. Rock worms (Marphysa victori) were provided by the Fishery Technology Center of PKNU (Goseong, Korea). Bait worms, krill, and barley kernels (bait grade) were obtained from a local market that sells bait in Busan, Korea. Handling and treatment of the experimental animals were conducted in accordance with governmental regulations and relevant standards. A Y-shaped acrylic tank (size of a single-arm: $48 \mathrm{~cm} \mathrm{~L} \times 33 \mathrm{~cm} \mathrm{~W} \times 28 \mathrm{~cm} \mathrm{H}$; Fig. 1A) was used to analyze the efficacy of the test foods for attracting juvenile rock bream (Jang et al., 2017). The housing and maintenance of the animals conformed to the regulations of The Institutional Animal Care and Use Committees of PKNU.

\section{Preparation of pellets containing test materials}

The internal tissues dissected from the outer shell of the sea urchin were tested for their ability to attract the fish along with worms and krill. Samples held at $-80^{\circ} \mathrm{C}$ were homogenized followed by freeze drying. A cellulose pellet (10\% corn flour in cellulose) was prepared by mixing $25.2 \mathrm{~g}$ of cellulose with 2.8 $\mathrm{g}$ of corn flour in $65 \mathrm{~mL}$ of water, and the mixture was passed through a $10-\mathrm{mL}$ disposable syringe without a needle (Duminda, 2020). After partial drying, the pellets were cut into $1-\mathrm{cm}$ lengths and air-dried. Freeze-dried samples $(0.2 \mathrm{~g})$ were resuspended in $1 \mathrm{~mL}$ of water and adsorbed onto a 1-g cellulose pellet followed by air drying (Fig. 1B). 
(A)

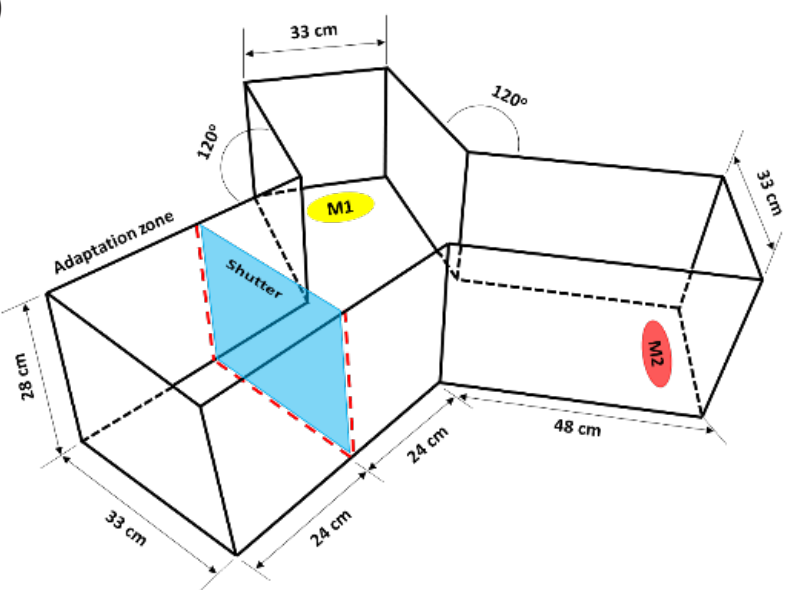

(B)

(1)

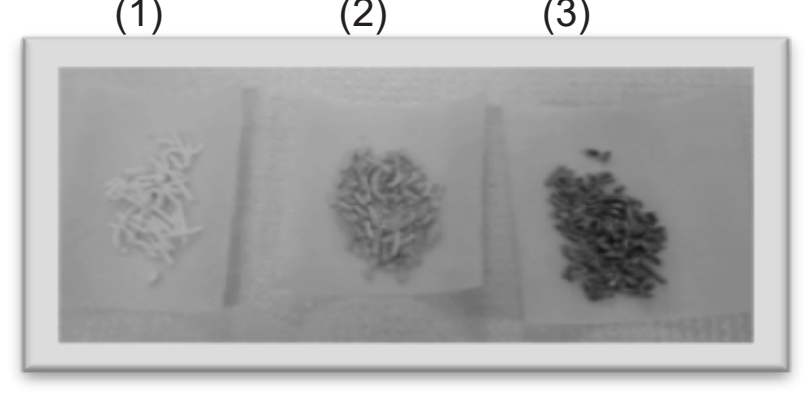

Fig. 1. Diagram of the Y-shape tank and photograph of pellets tested in this study. (A) Diagram showing the dimensions of the Y-shaped tank. Red and yellow ovals indicate the positions of pellets containing test food materials. The blue square indicates the position of the shield separating the acclimated fish from the test food materials. Once removed, the fish were exposed to the materials. (B) Photograph of pellets prepared for the rock bream behavioral analysis. These include cellulose pellets (1) and cellulose pellets with adsorbed extracts of rock worm (2) and sea urchin tissue (3).

\section{Rock bream behavioral analysis}

The fish were maintained in a rectangular tank and provided commercial feed ( $1 \%$ of body weight) daily but starved 1 day before the experiment. To monitor behavior, five randomly selected fish were acclimated for $15 \mathrm{~min}$ in the adaptive zone, which was separated by an acrylic shield from the other arms in the Y-shaped tank. The fish were exposed to food materials positioned near the ends of the other arms, as shown in Fig. 1A. Pellets containing a known amount of test material were inserted into an empty tea bag, which was then placed in a plastic container $(11 \mathrm{~cm} \times 8 \mathrm{~cm} \times 4 \mathrm{~cm})$ with slits in the lid. Plastic containers, each containing a test food, were positioned at the ends of the other arms. Fish movements were monitored for 15 min upon exposure to the test materials by removing the separating shield (Duminda, 2020).

\section{Vision-based automated tracking software}

The behavioral responses of rock bream were recorded by a camera fixed on top of the tank. Movement patterns were analyzed using EthoVision XT 10 (Noldus Information Technology, Leesburg, VA, USA) video tracking software. The analog video signals captured by the camera were digitized by a frame grabber for automated analysis as described previously (Noldus et al., 2001). Movement tracks were analyzed using heat maps and the occurrence frequency of fish detected in the designated zones around the test materials in the experimental tank as well as their duration of stay were recorded.

\section{Statistical analysis}

The experimental data are presented as the mean $\pm \mathrm{SD}$, and the statistical analysis was performed using the PASW statistical program ver.18 (IBM, Armonk, NY). Differences among experimental groups $(p<0.05)$ were examined using one-way analysis of variance and the paired $t$-test. A $p$-value $<0.05$ was considered to indicate significance.

\section{Results}

\section{Behavioral monitoring system for identifying attractive substances}

Video tracking systems have been used previously to monitor the behavioral responses of animals. To explore whether this system can be applied to investigations of aquatic animals, we tested this system by exposing rock bream to various test materials, including extracts of sea urchins and other bait candidates. Cellulose pellets containing amounts ranging from $0.1 \mathrm{~g}$ to 1.0 $\mathrm{g}$ of freeze-dried sample were prepared to determine the optimum amount that elicited a response. To examine the effect of a chemical diffused from the pellet, pellets containing the test materials were first covered with a tea bag, which was then 
placed in a plastic cage with slits in the lid to avoid any visual effect. For each trial, five fish of similar size were acclimated at one side of the designated arm in the Y-shaped tank, and their behaviors, such as quick movements with frequent rotation, frequent pecking at the ground and corners, and feeding movements, were observed to confirm the normal behavior of the fish in the tank. The fish movements were recorded for $15 \mathrm{~min}$ upon exposure to the pellets in the cages located at the ends of the opposite arms after removing the shield. The level of preference toward each test material was analyzed using a heat map and by assessing the duration of stay, occurrence frequency, and other behavioral parameters.

To test whether the system can be used to compare the attraction efficacy of each food type, control experiments were carried out with two pellets containing extracts of fish feed and barley kernel, which were positioned at each end of the test arms. Preliminary experiments indicated that $0.2 \mathrm{~g}$ of freezedried rock worm and sea urchin material induced attraction relative to the control pellets (data not shown). Preference toward each material was determined by the occurrence frequency, duration of stay, and the heat map of rock bream occurrence in the designated area in each arm with test material. The results showed a higher frequency of rock bream detected in the zone around commercial feed $(44.2 \pm 24.2)$ compared to that around barley kernel $(17.3 \pm 9.4)$, indicating a clear preference for the feed. A similar result was obtained based on duration of stay (120.7 \pm 56.7 vs. $39.3 \pm 16.3)$. To further confirm the result, another set of experiments was carried out with the same materials, but these were placed in opposite arms. The results also showed a higher frequency $(93.5 \pm 40.7)$ and duration of stay $(305.4 \pm 136.4)$ in the zone around the fish feed compared to barley (frequency $29.6 \pm 7.9$; duration $89.9+24.8$ ). The fish feed was a better attractant as shown by the heat map analysis; a higher intensity of red was observed than in the heat map for barley (Fig. 2), and an opposite pattern was observed in the reverse-orientation experiment. The results showed a consistent
(A)

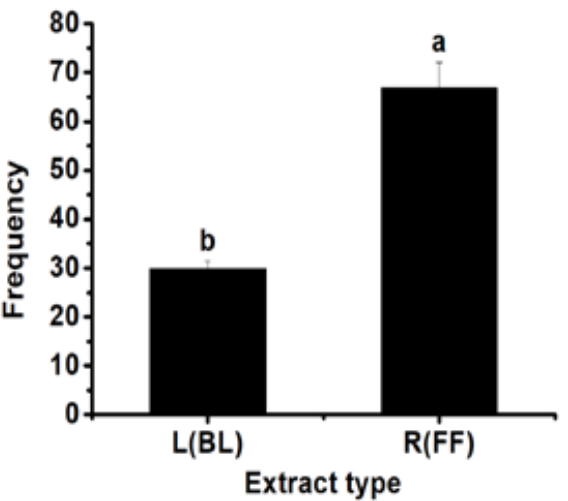

(B)

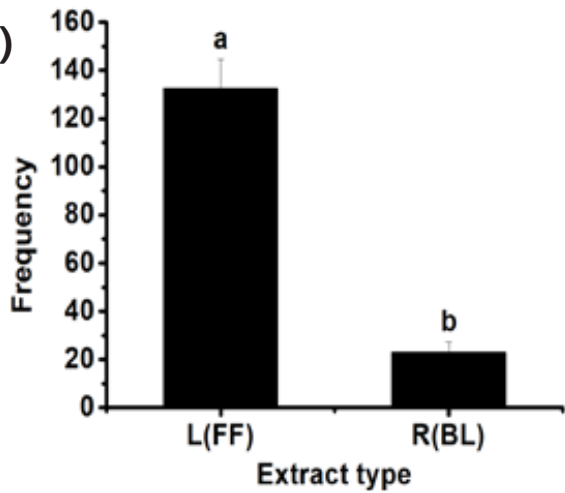

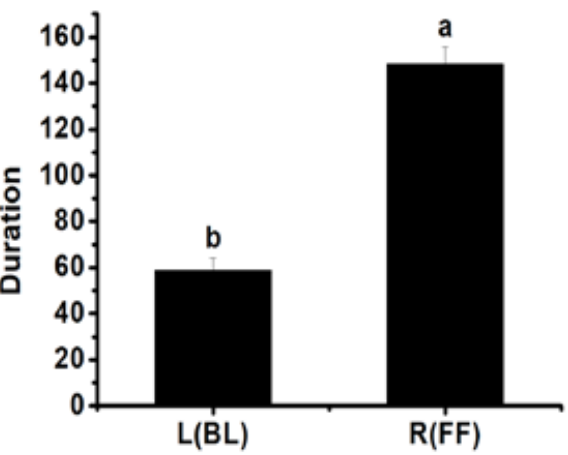

Extract type

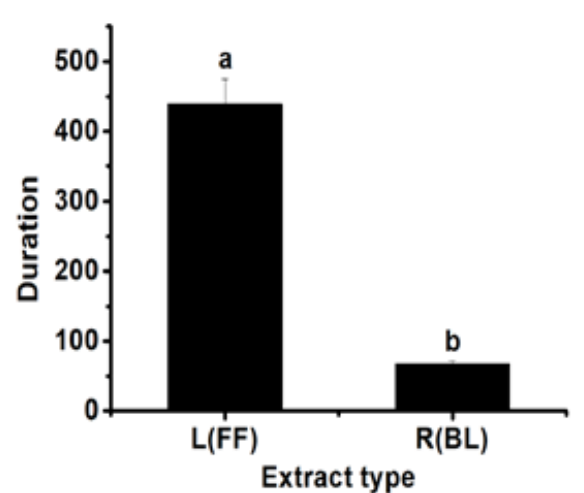

Extract type
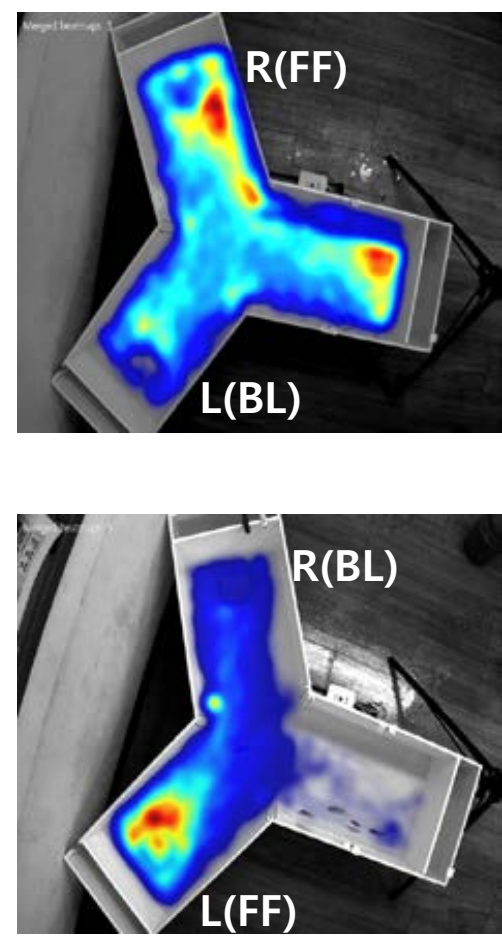

Fig. 2. Behavioral responses of the rock bream were analyzed upon exposure to fish feed (FF) and barley kernel (BL) located at the positions indicated. (A) The movement of the rock bream was first traced upon exposure to the materials located at the positions indicated. The second experiment was carried out with the same materials located at the opposite positions. (B) The occurrence frequency and duration of stay of rock bream detected in each zone ( $L$, left; $R$, right) were plotted based on values calculated from each analysis. Heat maps generated for each experiment are shown on the right. 
pattern for a stronger preference toward commercial feed compared to barley regardless of their positions in the tank, indicating that this video system can be used to compare the degree of attraction exerted by candidate materials.

\section{Analysis of rock bream attraction efficacy}

The attraction efficacy of the materials containing worms and krill, which are commonly used as bait for fishing, was tested. It was of particular interest to explore the potential attraction efficacy of sea urchin compared to the other materials, which include fish feed, krill, bait worm, rock worm, and barley. An initial experiment was carried out in a rectangular tank (data not shown), and the Y-shaped tank was used to compare the relative preference between materials located at each end of the two test arms in the tank. Experiments were carried out with a pellet containing sea urchin extract on one side together with a pellet containing another material on the other side. Fig. 3 shows the heat maps reflecting rock bream occurrence around the test food materials, indicating a stronger preference toward the sea urchin extract than the other materials, including krill, worms, and barley, except the commercial fish feed, which was most highly preferred. The relative preference toward each test material was calculated from a comparison of the frequency of fish detected in each zone. The results showed a relative preference toward commercial fish feed, krill, bait worm, rock worm, and barley of $175 \pm 34.9 \%, 90.1 \pm 44.2 \%, 81.1 \pm 39.1 \%, 73.7 \pm$ $28.9 \%$, and $63.9 \pm 25.9 \%$, respectively, compared to sea urchin, whose preference level was set to $100 \%$ (Fig. 4). These results indicated that the highest preference $(p<0.05)$ was for the commercial fish feed followed by sea urchin. The lowest response was to barley.

To compare the differences among materials with a moderate level of preference, further analysis was carried out to directly compare between two materials, including krill vs. rock worm, krill vs. bait worm, and rock worm vs. bait worm. The frequency and duration of attraction by rock bream to those pairs of material cues are displayed in Fig. 5 along with their representative heat maps. The results showed that the respective frequency $(74 \pm 29.8$ and $86.3 \pm 22.9)$ and duration $(375.6 \pm 118.8$ and $477.1 \pm 84)$ of the attraction to krill in both experiments were significantly higher than those to rock worm (frequency $41.5 \pm 18.7$, duration $160.2 \pm 42.6$ ) and bait worm (frequency $36.2 \pm 5.5$, duration $166.1 \pm 50.7$ ). The frequency $(45.3 \pm 25.2)$ and duration $(212.9 \pm 102.5)$ values reflecting rock bream attraction toward rock worm were higher than those to-
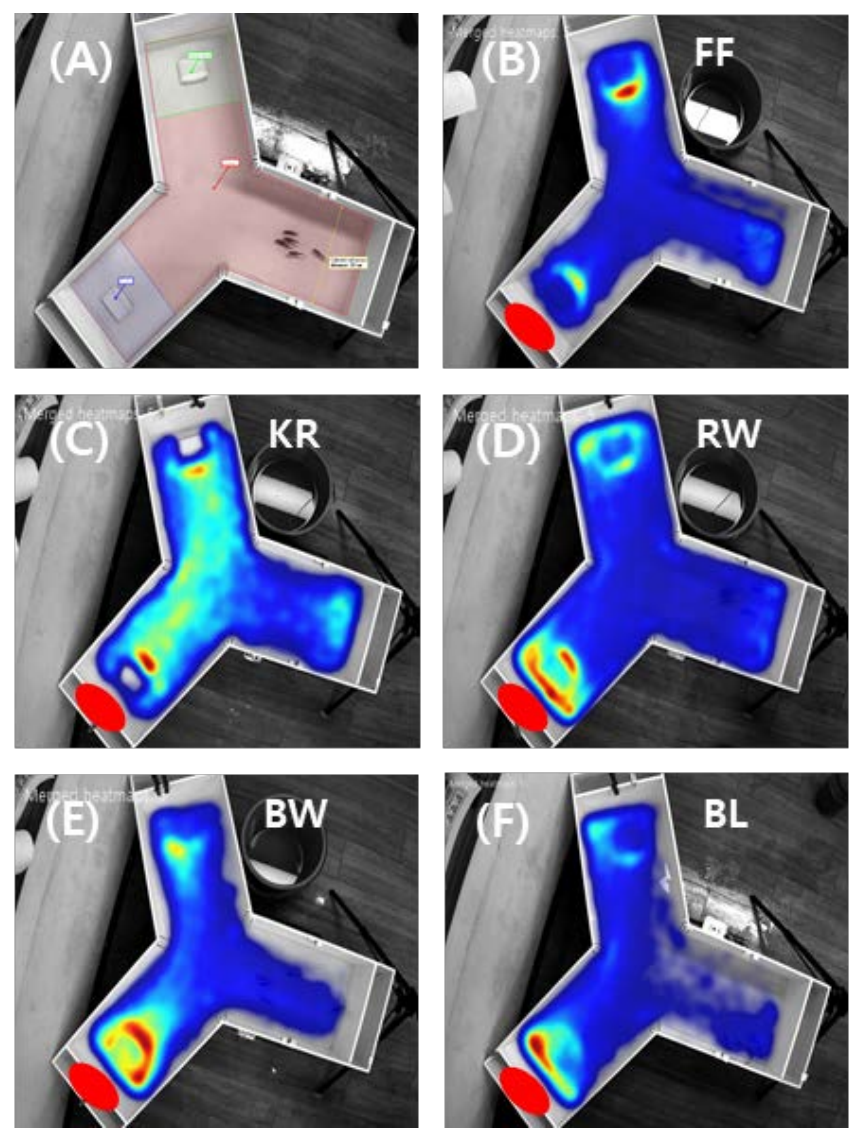

Fig. 3. Photograph showing the area and zones in the Y-shaped tank used for the rock bream behavioral analysis (A), and heat maps reflecting fish movements (B-F). Heat maps were generated by tracing fish movements that were recorded upon exposure to the pellets. In each trial, one pellet contained sea urchin extract (red oval) and the other contained an extract of commercial fish feed (FF, B), krill $(\mathrm{KR}, \mathrm{C})$, rock worm (RW, D), bait worm (BW, E), or barley (BL, F).

ward bait worm (frequency 34.6 \pm 20.6 , duration $159.1 \pm 94.2$ ) ( $p$ $<0.05)$. Overall, these results indicate that the rock bream's preference toward the test materials was in the following order: fish feed $>>$ sea urchin $>$ krill $>$ rock worm $>$ bait worm $>>$ barley.

\section{Discussion}

\section{Attraction potential of the sea urchin extract}

A behavioral response analysis of fish is one of the simplest and most efficient ways to assess the attraction ability of chemical and visual signals to elicit foraging, courtship, schooling, attracting-evading, or defensive behaviors (Firestein, 2001; Kermen et 


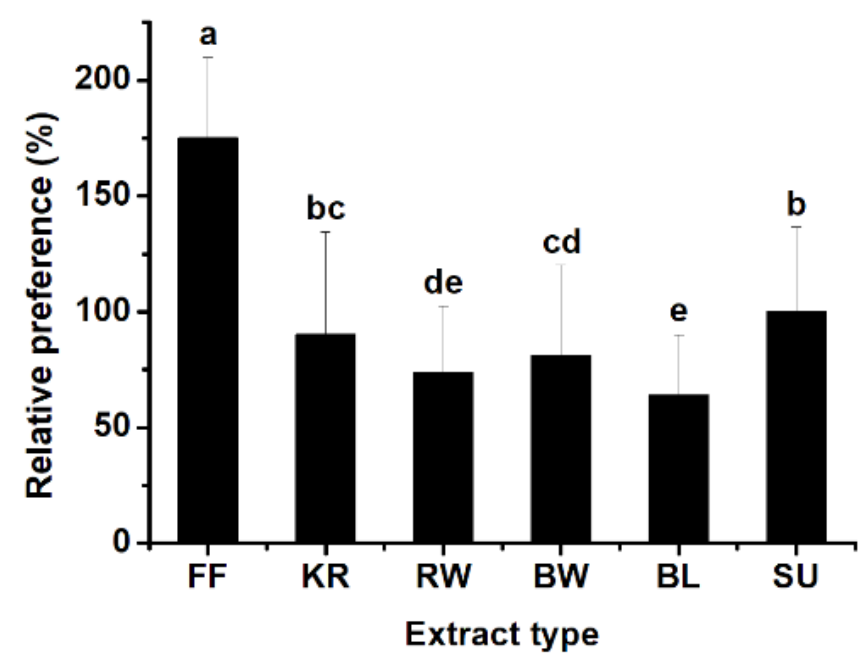

Fig. 4. Relative preference (\%) as reflected by rock bream movements toward pellets containing fish feed (FF), krill (KR), rock worm (RW), bait worm (BW), barley (BL), or sea urchin (SU) extracts. Each analysis was carried out with two kinds of pellets-one containing sea urchin at one end, and the other containing an extract of $\mathrm{FF}, \mathrm{KR}, \mathrm{RW}, \mathrm{BW}$, or $\mathrm{BL}$ at the other end. Relative preference was calculated from the frequency of rock bream detected in the zone containing the test food material compared to that of sea urchin. Different lowercase letters $\left({ }^{a-e}\right)$ denote a significant difference.

al., 2013; Mas-Muñoz et al., 2011). Chemical cues play a major role in stimulating food-searching behavior to locate the source of an odorant (Atema, 1980; Vabø et al., 2004). A range of low molecular weight substances, such as amino acids, peptides, terpenoids, nucleotides, nucleosides, fatty acids, bile acids, organic acids, sugars, and other chemicals (Braubach et al., 2011; Carr \& Derby, 1986; Elkins et al., 2009; Goh \& Tamura, 1980; Johnsen \& Adams, 1986) derived from metabolites or chemical stimuli of prey organisms attract fish (Arimoto, 1997; Little \& Brewer, 2001; Løkkeborg et al., 2014; Vabø et al., 2004). Apart from these chemical cues, visual cues attract fish toward bait, of which the shape, size, color, and chemical composition are key factors for attracting fish (Alós et al., 2009), which affects the yield and type of fish caught (Broadhurst \& Hazin, 2001; Lowry et al., 2006; Smith, 2002; Woll et al., 2001). Therefore, selecting bait with a strong attraction efficacy based on food and feeding habits is important for promoting target fish catchability (Umar et al., 2018).

Several species, such as worms and krill, are popular fishing bait and feed components (Suresh et al., 2011). Various efforts have been focused on developing user and environmentally friendly bait alternatives that can be purchased at a low cost. To be successfully developed as a bait alternative, the target substance should contain at least the threshold level of the chemical cue needed for attracting fish. To identify such a material, we developed a video-based system to screen materials that elicit an attractive response in fish. The reliability of the system was tested with rock bream and two food items-commercial fish feed and barley kernels, which exhibited the highest and lowest attraction efficacy, respectively. A clear preference toward the feed relative to the barley indicated that the system can be applied to identify materials that attract fish. The analysis of rock bream movements in response to the materials offered indicated preference for the materials in the following order: commercial feed $>$ sea urchin $>$ rock worm $>$ bait worm $>$ krill $>$ barley kernel. Commercial feed might have been most strongly preferred due to the ingredient composition of the fish meal (Suresh et al., 2011), although we cannot exclude the effect of farmed fish being adapted to commercial feed. It might have also originated from higher soluble component levels in the feed compared to those in the other materials, which may contain higher muscle or cuticle contents that are not easily soluble (e.g., myofibrillar, alkali-soluble, or stromal proteins). A stronger preference toward sea urchin compared to common bait items (rock worm, bait worm, and krill) could be due to the fact that rock bream typically eat benthic mollusks and crustaceans (i.e., hardshelled snails and barnacles). The gonads of some sea urchins, which have a distinctive aroma and taste, are used as food and nutraceuticals in some countries (Qin et al., 2011; Siliani et al., 2016; Zhao et al., 2018). Despite their usefulness, sea urchins that overgraze seaweed areas in large numbers can threaten the marine forest environment, by indirectly affecting other marine fauna through their foraging impacts. To protect the marine environment and algal biodiversity, controlling the number of sea urchins that invade seaweed areas is a large challenge in marine production. Thus, the sea urchin population should be controlled from an ecological perspective and the biomass collected consequently should be used effectively. Our study showed that rock bream was more attracted to sea urchin extract compared to those of worms and krill, which have been popularly used as fishing bait. Given that a large amount of sea urchin biomass is expected to be accumulated with control efforts, our findings suggest that sea urchins could be used as a bait alternative. This would be an innovative solution for using up large amounts of sea urchin biomass in an environmentally friendly manner. 
(A)

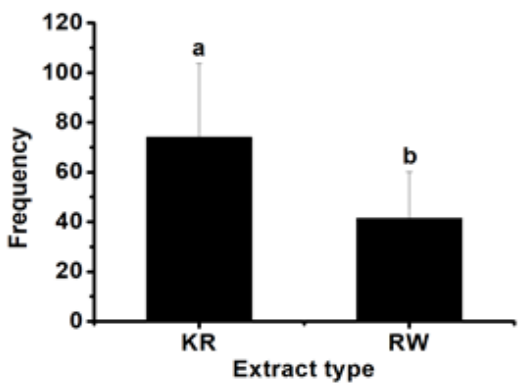

(B)

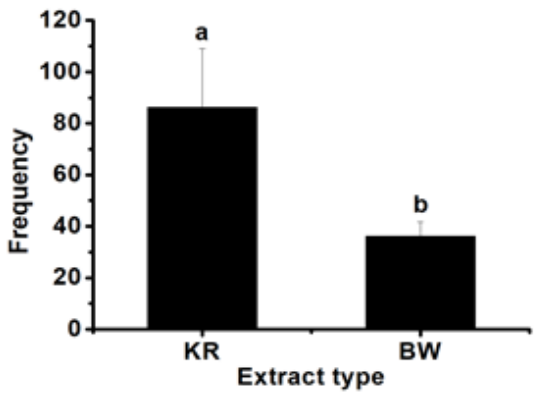

(C)

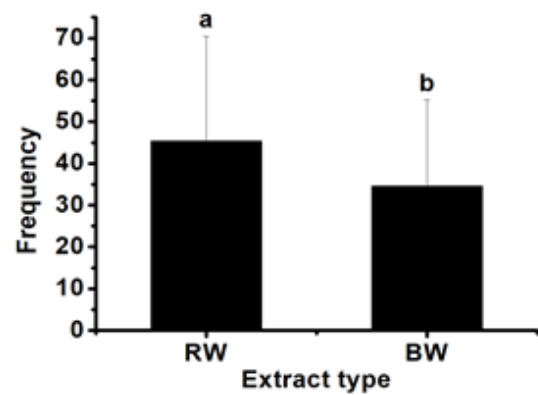

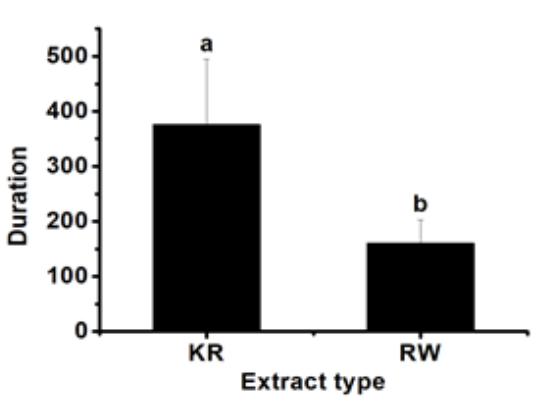
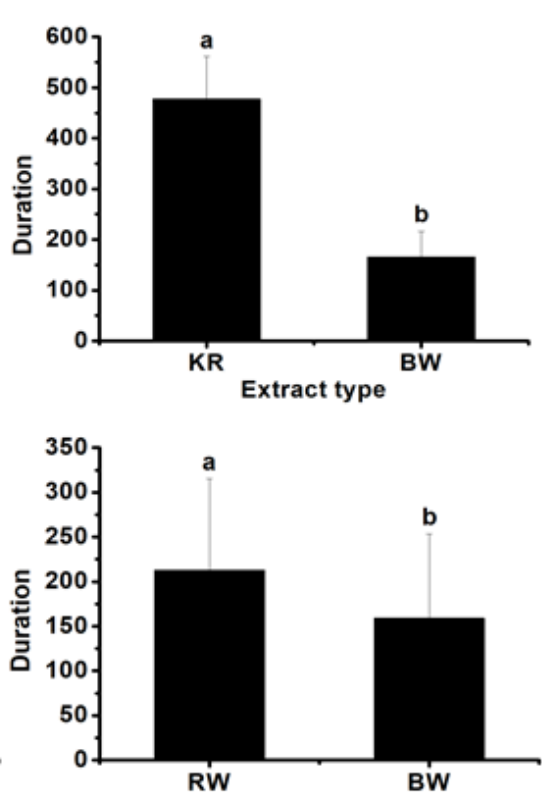

Extract type
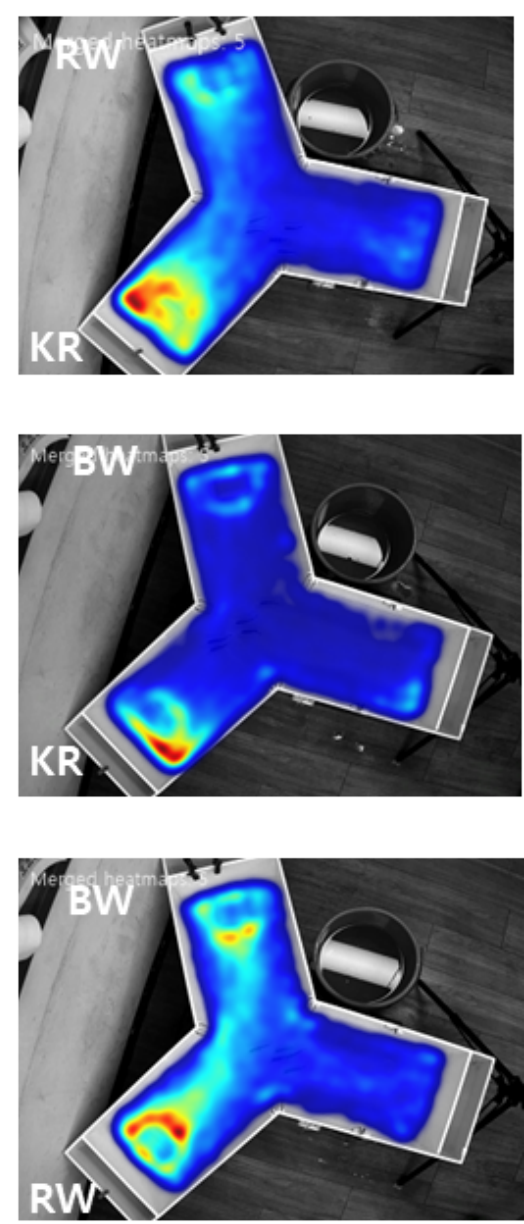

Fig. 5. Behavioral analysis of rock bream to compare differences in preference toward krill (KR), rock worm (RW), and bait worm (BW). The heat map was acquired from rock bream movements upon exposure to pellets containing test food materials at each end. Comparisons were carried out between krill and rock worm (A), krill and bait worm (B), and rock worm and bait worm (C) in a Y-shaped tank, as indicated. Relative preference was calculated from the frequency and duration of stay of rock bream detected in the corresponding zones.

Additionally, a video tracking system was successfully applied to monitor the movements of rock bream, and this application can be extended to other aquaculture species. Specifically, the system can be successfully applied to identify chemical cues that attract or repel target organisms.

\section{Competing interests}

No potential conflict of interest relevant to this article was reported.

\section{Funding sources}

This research was financially supported by research grant of
Pukyong National University (2019).

\section{Acknowledgements}

This work was supported by a Research Grant of Pukyong National University (2019 year).

\section{Availability of data and material}

Upon reasonable request, the datasets of this study can be available from the corresponding author.

\section{Ethics approval and consent to participate}

The housing and maintenance of the animals conformed to the 
regulations of The Institutional Animal Care and Use Committees of Pukyong National University.

\section{References}

Agatsuma Y. Ecology of Strongylocentrotus nudus. In: Lawrence JM, editor. Edible sea urchins: biology and ecology. 2nd ed. Amsterdam, Nederland: Elsevier Science; 2007. p.443-57.

Alós J, Arlinghaus R, Palmer M, March D, Álvarez I. The influence of type of natural bait on fish catches and hooking location in a mixed-species marine recreational fishery, with implications for management. Fish Res. 2009;97:270-7.

Arimoto T. Fish behaviour approach for improving trawl gear selectivity: In: Proceeding of the Regional Workshop on Responsible Fishing; 1997; Bangkok, Thailand. p.251-65.

Atema J. Chemical senses, chemical signals and feeding behavior in fishes. In: Bardach JE, Magnuson JJ, May RC, Reinhart JM, editors. Fish behavior and its use in the capture and culture of fishes. Pulau Pinang, Philippines: International Center for Living Aquatic Resources Management; 1980. p.57-101.

Braubach OR, Wyeth RC, Murray A, Fine A, Roger PC. A simple and effective method to condition olfactory behaviors in groups of zebrafish. In: Kalueff AV, Cachat M, editors. Zebrafish neurobehavioral protocols. New York, NY: Humana Press; 2011. p.85-97.

Broadhurst MK, Hazin FHV. Influences of type and orientation of bait on catches of swordfish (Xiphias gladius) and other species in an artisanal sub-surface longline fishery off northeastern Brazil. Fish Res. 2001;53:169-79.

Carr WES, Derby CD. Chemically stimulated feeding behavior in marine animals. J Chem Ecol. 1986;12:989-1011.

Duminda SKTC. Behavior analysis of sea urchin Strongylocentrotus nudus and rock bream Oplegnathus fasciatus for identifying chemical cues eliciting attractant/repellant responses [M.S. Thesis]. Busan: Pukyong National University; 2020.

Elkins A, Barrow R, Rochfort S. Carp chemical sensing and the potential of natural environmental attractants for control of carp: a review. Environ Chem. 2009;6:357-68.

Firestein S. How the olfactory system makes sense of scents. Nature. 2001;413:211-8.

Goh Y, Tamura T. Effect of amino acids on the feeding behaviour in red sea bream. Comp Biochem Physiol C Comp
Pharmacol. 1980;66:225-9.

Jang JC, Chung JK, Hur YS, Song JH, Kim JM. Behavioral monitoring system for mud shrimp Upogebia major and the photoresponse to illumination with different wavelength LEDs. Korean J Fish Aquat Sci. 2017;50:413-20.

Jang JC, Choi MJ, Yang YS, Lee HB, Yu YM, Kim JM. Dim-light photoreceptor of chub mackerel Scomber japonicus and the photoresponse upon illumination with LEDs of different wavelengths. Fish Physiol Biochem. 2016;42:1015-25.

Johnsen PB, Adams MA. Chemical feeding stimulants for the herbivorous fish, Tilapia zillii. Comp Biochem Physiol A Physiol. 1986;83:109-12.

Harrold C, Pearse JS. The ecological role of echinoderms in kelp forests. In: Jangoux M, Lawrence JM, editors. Echinoderm studies. Boca Raton, FL: CRC Press; 1987. p.137-233.

Kane AS, Salierno JD, Brewer SK. Fish models in behavioral toxicology: automated techniques, updates and perspectives. In: Ostrander GK, editor. Methods in aquatic toxicology. Baton Rouge, FL: CRC Press; 2005. p.559-590.

Kermen F, Franco LM, Wyatt C, Yaksi E. Neural circuits mediating olfactory-driven behavior in fish. Front Neural Circuits. 2013;7:62.

Kuklina I, Kouba A, Kozák P. Real-time monitoring of water quality using fish and crayfish as bio-indicators: a review. Environ Monit Assess.2013;185:5043-53.

Lang C, Mann KH. Change in sea urchin populations after the destruction of kelp beds. Mar Biol. 1976;36:321-6.

Lawrence JM. Sea urchin: biology and ecology. 2nd ed. Amsterdam: Elsevier Science; 2007.

Little EE, Brewer SK. Neurobehavioral toxicity in fish. In: D Schlenk, Benson WH, editors. Target organ toxicity in marine and freshwater teleosts. London: Taylor and Francis; 2001. p.141-76.

Løkkeborg S, Siikavuopio SI, Humborstad OB, Utne-Palm AC, Ferter K. Towards more efficient longline fisheries: fish feeding behaviour, bait characteristics and development of alternative baits. Rev Fish Biol Fisher. 2014;24:985-1003.

Lowry M, Steffe A, Williams D. Relationships between bait collection, bait type and catch: a comparison of the NSW trailer-boat and gamefish-tournament fisheries. J Fisher Res. 2006;78:266-75.

Mas-Muñoz J, Komen H, Schneider O, Visch SW, Schrama JW. Feeding behavior, swimming activity and boldness explain variation in feed intake and growth of Sole (Solea solea) reared in captivity. PLOS ONE. 2011;6:e21393. 
Niu B, Li G, Peng F, Wu J, Zhang L, Li Z. Survey of fish behavior analysis by computer vision. J Aquac Res Dev. 2018;9:1-15.

Noldus LPJJ, Spink AJ, Tegelenbosch RAJ. EthoVision: a versatile video tracking system for automation of behavioral experiments. Behav Res Methods Instrum Comput. 2001;33:398-414.

Qin L, Zhu BW, Zhou DY, Wu HT, Tan H, Yang JF, et al. Preparation and antioxidant activity of enzymatic hydrolysates from purple sea urchin (Strongylocentrotus nudus) gonad. LWT-Food Sci Technol. 2011;44:1113-8.

Rune V, Geir H, Anders F, Terje J, Svein L, Georg S. Simulating search behaviour of fish towards bait. ICES J Marine Sci. 2004;61:1224-32.

Smith PA. The relationship between stock and catch and the effect of bait on catch as determined for a UK recreational catch and release fishery. Fish Manage Ecol. 2002;9:261-6.

Siliani S, Melis R, Loi B, Guala G, Baroli M, Sanna S, et al. Influence of seasonal and environmental patterns on the lipid content and fatty acid profiles in gonads of the edible sea urchin Paracentrotus lividus from Sardinia. Mar Environ Res. 2016;113:124-33.

Suresh AV, Kumaraguru vasagam KP, Nates S, Attractability and palatability of protein ingredients of aquatic and terrestrial animal origin, and their practical value for blue shrimp, Litopenaeus stylirostris fed diets formulated with high levels of poultry byproduct meal. Aquaculture 2011;319:132-40.

Umar T, Sitkun D, Asri A. The influence of using bait types to the number and composition of fishing traps catch in south ternate waters. IOP Conf Ser Earth Environ Sci. 2018;175:012231.

Vabø R, Huse G, Fernö A, Jørgensen T, Løkkeborg S, Skaret G. Simulating search behaviourof fish towards bait. ICES J Mar Sci. 2004;61:1224-32.

Valentine JF, Heck KL. Seagrass herbivory: evidence for the continued grazing of marine grasses. Mar Ecol Prog Ser.1999;176:291-302.

Woll AK, Boje J, Holst R, Gundersen AC. Catch rates and hook and bait selectivity in longline fishery for Greenland halibut (Reinhardtius hippoglossoides, Walbaum) at East Greenland. Fish Res. 2001;51:237-46.

Zhao S, Cheng Q, Peng Q, Yu X, Yin X, Liang M, et al. Antioxidant peptides derived from the hydrolyzate of purple sea urchin (Strongylocentrotus nudus) gonad alleviate oxidative stress in Caenorhabditis elegans. J Funct Food. 2018;48:594-604. 